\title{
Highly regio- and stereoselective phosphinylphosphination of terminal alkynes with tetraphenyldiphosphine monoxide under radical conditions
}

\author{
Dat Phuc Tran ${ }^{1}$, Yuki Sato ${ }^{1}$, Yuki Yamamoto ${ }^{1}$, Shin-ichi Kawaguchi ${ }^{* 2}$, \\ Shintaro Kodama ${ }^{* 1}$, Akihiro Nomoto ${ }^{1}$ and Akiya Ogawa ${ }^{* 1}$
}

\section{Full Research Paper}

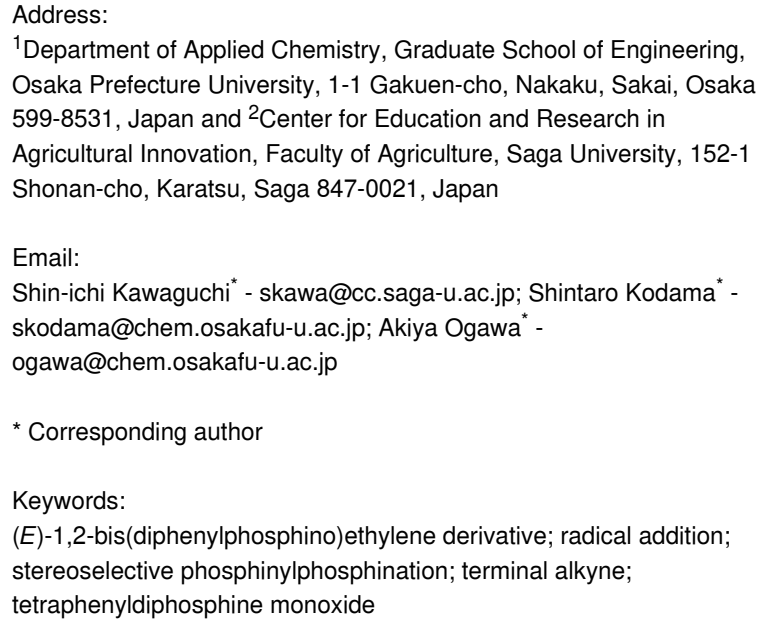

${ }^{1}$ Department of Applied Chemistry, Graduate School of Engineering, Osaka Prefecture University, 1-1 Gakuen-cho, Nakaku, Sakai, Osaka 599-8531, Japan and ${ }^{2}$ Center for Education and Research in Agricultural Innovation, Faculty of Agriculture, Saga University, 152-1 Shonan-cho, Karatsu, Saga 847-0021, Japan

Email:

Shin-ichi Kawaguchi* - skawa@cc.saga-u.ac.jp; Shintaro Kodama* skodama@chem.osakafu-u.ac.jp; Akiya Ogawa* -

ogawa@chem.osakafu-u.ac.jp

* Corresponding author

Keywords:

(E)-1,2-bis(diphenylphosphino)ethylene derivative; radical addition; stereoselective phosphinylphosphination; terminal alkyne;

tetraphenyldiphosphine monoxide

\author{
Beilstein J. Org. Chem. 2021, 17, 866-872. \\ https://doi.org/10.3762/bjoc.17.72 \\ Received: 10 February 2021 \\ Accepted: 07 April 2021 \\ Published: 20 April 2021 \\ Associate Editor: S. Bräse \\ () 2021 Tran et al.; licensee Beilstein-Institut. \\ License and terms: see end of document.
}

\begin{abstract}
The homolytic cleavage of the $\mathrm{P}^{\mathrm{V}}(\mathrm{O})-\mathrm{P}^{\mathrm{III}}$ bond in tetraphenyldiphosphine monoxide simultaneously provides both pentavalent and trivalent phosphorus-centered radicals with different reactivities. The method using V-40 as an initiator is successfully investigated for the regio- and stereoselective phosphinylphosphination of terminal alkynes giving the corresponding trans-isomers of 1-diphenylphosphinyl-2-diphenylthiophosphinyl-1-alkenes in good yields. The protocol can be applied to a wide variety of terminal alkynes including both alkyl- and arylalkynes.
\end{abstract}

\section{Introduction}

Organophosphorus compounds are an essential class of compounds in catalytic technologies, biochemistry, and materials [1-6]. In particular, in coordination chemistry and catalyst chemistry, organophosphorus compounds such as triorganylphosphines are widely used as typical monodentate ligands for many metals $[7,8]$. In addition, diphosphines such as 1,2-bis(diphenylphosphino)ethane $\left(\mathrm{Ph}_{2} \mathrm{PCH}_{2} \mathrm{CH}_{2} \mathrm{PPh}_{2}\right.$, dppe) are employed as bidentate ligands and are effective in controlling important catalytic reactions such as cross-coupling reactions [9-18]. 1,2-Bis(diphenylphosphino)ethylene 
$\left(\mathrm{Ph}_{2} \mathrm{PCH}=\mathrm{CHPPh}_{2}\right.$, dppen $)$ is among bidentate diphosphine ligands having a rigid structure and has increased attention as a useful and effective ligand in coordinating with various metals $[19,20] .(Z)-\mathrm{Ph}_{2} \mathrm{PCH}=\mathrm{CHPPh}_{2}$ is very important as a bidentate ligand for many mononuclear complexes [21-23]. On the other hand, $(E)-\mathrm{Ph}_{2} \mathrm{PCH}=\mathrm{CHPPh}_{2}$ acts as a monodentate ligand for mononuclear complexes, but it is highly attractive because a hierarchical structure can be constructed by cross-linking between two metals [24-26]. Considering the characteristics of the coordination form between the $(E)$ - and $(Z)$-isomers, the development of a synthetic method for the highly selective synthesis of the $(E)$ - or (Z)-isomers is strongly desired [27-30]. Furthermore, since it was reported that the introduction of a substituent into the ethylene moiety has a great effect on the catalytic activity [31], it is considered important to synthesize derivatives having various substituents on the ethylene moiety. In particular, synthetic methods that do not use metal catalysts and reagents are expected to be very effective in manufacturing precision materials and pharmaceuticals [32-37]. To develop metal-free methods for the synthesis of 1,2-bis(diphenylphosphino)ethylenes, we have recently been conducting systematic research on the radical addition of $\mathrm{P}-\mathrm{P}$ bond compounds to unsaturated carbon-carbon bonds [38-44]. Early studies have found that the radical addition of tetraphenyldiphosphine $\left(\mathrm{Ph}_{2} \mathrm{PPPh}_{2}\right)$ to alkynes using a radical initiator such as $1,1^{\prime}$ azobis(cyclohexane-1-carbonitrile) (V-40) (Scheme 1a) [45] or

radical addition of $\mathrm{Ph}_{2} \mathrm{PPPh}_{2}$ to terminal alkynes

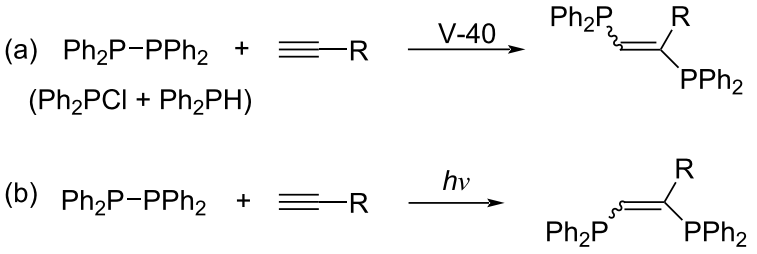

radical addition of $\mathrm{Ph}_{2} \mathrm{P}(\mathrm{X}) \mathrm{PPh}_{2}$ to alkenes<smiles></smiles>

$\mathrm{Ph}_{2} \stackrel{\text { PI }}{\mathrm{P}}-\mathrm{PPh}_{2}$
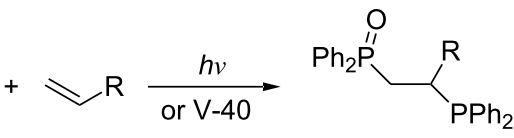

(d) S<smiles>PP(=S)(c1ccccc1)P(P=S)c1ccccc1</smiles>
$+\gtrsim \mathrm{R} \stackrel{h v}{\longrightarrow}$

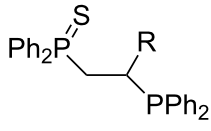

this work: radical addition of $\mathrm{Ph}_{2} \mathrm{P}(\mathrm{O}) \mathrm{PPh}_{2}$ to terminal alkynes<smiles>[2H]P=[18O]</smiles>

Scheme 1: Radical rated $\mathrm{C}-\mathrm{C}$ bonds. upon photoirradiation (Scheme 1b) [38] yields vic-bis(diphenylphosphino)alkenes in good yields. Unfortunately, this photoinduced reaction of $\mathrm{Ph}_{2} \mathrm{PPPh}_{2}$ was not applicable to alkenes [42]. To change the reactivity of the $\mathrm{P}-\mathrm{P}$ bond, therefore, when the combination of pentavalent phosphorus and trivalent phosphorus was examined, it was found that the desired radical addition of $\mathrm{Ph}_{2} \mathrm{P}(\mathrm{X}) \mathrm{PPh}_{2}(\mathrm{X}=\mathrm{O}, \mathrm{S})$ to alkenes successfully occurred [42,43] (Scheme 1c and 1d).

However, in the case of $\mathrm{Ph}_{2} \mathrm{P}(\mathrm{O}) \mathrm{PPh}_{2}$, its absorption is located at a shorter wavelength $\left(\lambda_{\max }=318 \mathrm{~nm}\right)$ and the absorption intensity is lower than those of $\mathrm{Ph}_{2} \mathrm{PPPh}_{2}$ and $\mathrm{Ph}_{2} \mathrm{P}(\mathrm{S}) \mathrm{PPh}_{2}$ [46]. Indeed, the photoinduced addition of $\mathrm{Ph}_{2} \mathrm{P}(\mathrm{O}) \mathrm{PPh}_{2}$ to alkynes required prolonged reaction times $(>40 \mathrm{~h})$, and the scope of this alkyne addition was unexamined. Thus, we examined in detail the radical addition of $\mathrm{Ph}_{2} \mathrm{P}(\mathrm{O}) \mathrm{PPh}_{2}$ to alkynes and found that the desired radical addition proceeds efficiently using a radical initiator instead of light irradiation, providing 1-(diphenylphosphinyl)-2-(diphenylphosphino)-1-alkenes (Scheme 1e).

\section{Results and Discussion}

First, a mixture of $\mathrm{Ph}_{2} \mathrm{P}(\mathrm{O}) \mathrm{PPh}_{2}(\mathbf{1}, 0.6 \mathrm{mmol})$ and 1-octyne (2a, $0.4 \mathrm{mmol}$ ) was irradiated with a xenon lamp. After 40 hours, sulfurization of the addition product was performed to afford the phosphinylphosphination product 3a in $45 \%$ yield, confirmed by ${ }^{31} \mathrm{P}$ NMR spectroscopy (Scheme 2) [47].

$$
\begin{aligned}
& \mathrm{Ph}_{2} \stackrel{\mathrm{P}-\mathrm{PPh}_{2}}{1}+\equiv n \text {-Hex } \frac{\text { Xe lamp }}{\mathrm{CDCl}_{3}(0.4 \mathrm{~mL})} \\
& \begin{array}{cc}
1 & 2 a \\
0.6 \mathrm{mmol} & 0.4 \mathrm{mmol}
\end{array}
\end{aligned}
$$

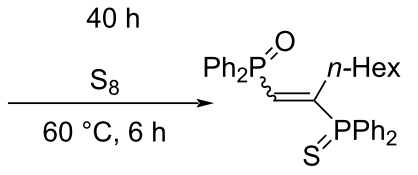

$$
\begin{aligned}
& \text { 3a, } 45 \% \\
& E / Z=98: 2
\end{aligned}
$$

Scheme 2: The addition of $\mathrm{Ph}_{2} \mathrm{P}(\mathrm{O}) \mathrm{PPh}_{2}$ (1) to 1-octyne (2a).

Next, the reaction was carried out varying the reaction parameters such as the light source and the ratio of the radical initiator (V-40)/2a (Table 1). Using a xenon lamp as an artificial solar source [48,49], 3a was produced in $45 \%$ yield (Table 1, entry 1). Using UV light irradiation with a high-pressure mercury lamp [50], 3a was produced in $28 \%$ yield (Table 1, entry 2). However, 3a was obtained only in trace amounts upon irradiation with a tungsten lamp [51] (Table 1, entry 3). These results indicate that $\mathrm{Ph}_{2} \mathrm{P} \bullet$ [52-55] and/or $\mathrm{Ph}_{2} \mathrm{P}(\mathrm{O}) \bullet$ [56-59] radicals were generated by the irradiation with light in the near-UV region. When benzene was used instead of $\mathrm{CDCl}_{3}$ under xenon 
Table 1: Phosphinylphosphination of terminal alkyne $2 \mathrm{a}$ with 1 under different reaction parameters.

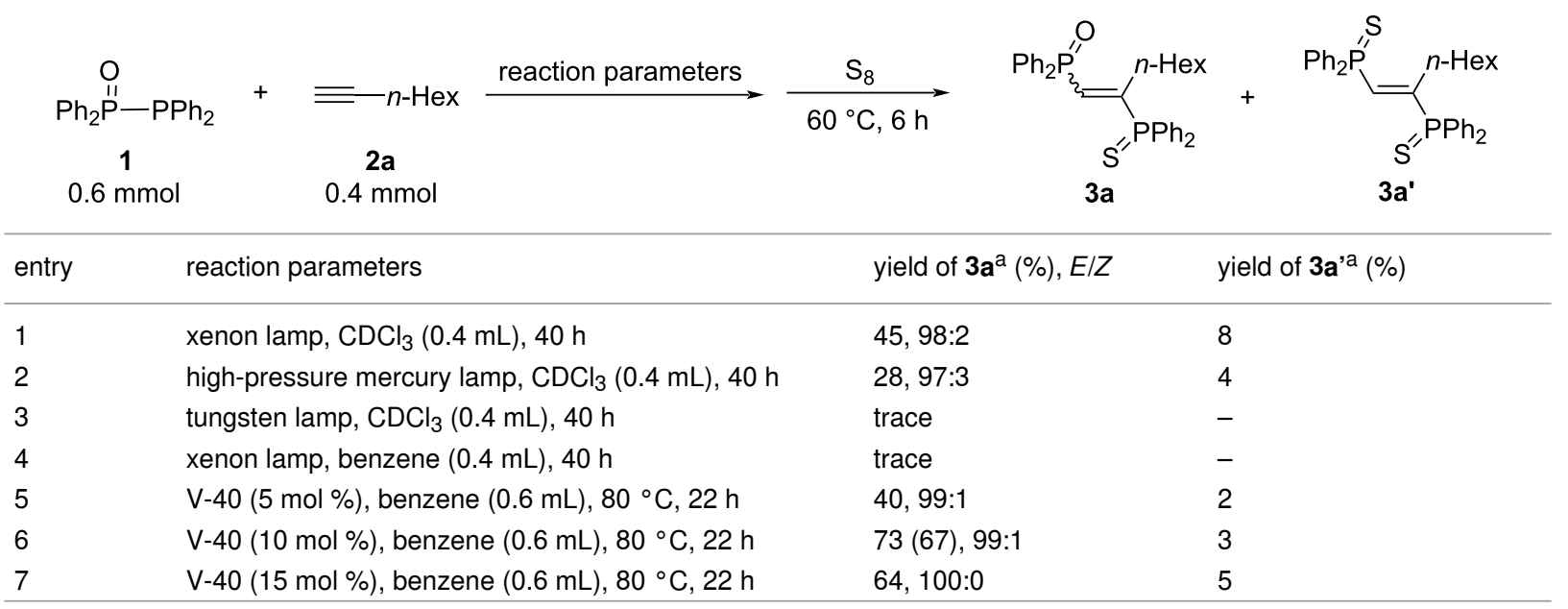

aDetermined by ${ }^{31} \mathrm{P}$ NMR spectroscopy. V-40 = 1,1'-azobis(cyclohexane-1-carbonitrile). Isolated yield is shown in parentheses.

lamp irradiation, the reaction did not proceed because $\mathbf{1}$ was less soluble in benzene than $\mathrm{CDCl}_{3}$ (Table 1, entry 4). The radical initiator, $\mathrm{V}-40$, was found to be an appropriate initiator for the generation of phosphorus-centered radicals $[38,42]$. The ratio of V-40/2a was important to depress the formation of selfpolymerization of 2a (Table 1, entries 5-7). The results showed that the best amount of V-40 toward 2 a was $10 \mathrm{~mol} \%$. Besides, the side product $\mathbf{3 a}$ ' is found up to $8 \%$ yield under photoirradiation. Considering that in our previously reported radical addition reactions of $\mathrm{Ph}_{2} \mathrm{P}(\mathrm{S}) \mathrm{PPh}_{2}$ and $\mathrm{Ph}_{2} \mathrm{P}(\mathrm{S}) \mathrm{P}(\mathrm{S}) \mathrm{Ph}_{2}$ to alkynes [44], the $E / Z$ ratios were about $9: 1$ and 8:2, respectively, it should be noted that the present addition of $\mathrm{Ph}_{2} \mathrm{P}(\mathrm{O}) \mathrm{PPh}_{2} 1$ to alkynes afforded $(E)$-isomers with an excellent stereoselectivity (greater than 95:5) [60].

The phosphinylphosphination of various terminal alkynes 2 with $\mathrm{Ph}_{2} \mathrm{P}(\mathrm{O}) \mathrm{PPh}_{2} 1$ was conducted under the optimization conditions (Scheme 3). Terminal alkylalkynes $\mathbf{2 a}, \mathbf{2 b}$, and $\mathbf{2 c}$ reacted efficiently with $\mathbf{1}$ to give the corresponding adducts $\mathbf{3 a}$, $\mathbf{3 b}$, and $\mathbf{3 c}$ in moderate to good yields $(67 \%, 71 \%$, and $83 \%$, respectively) with excellent stereoselectivity $(E / Z=95: 5-99: 1)$. Terminal alkylalkynes with chloro (2d), cyano (2e), and ester (2g) groups provided the corresponding adducts $\mathbf{3 d}, \mathbf{3 e}$, and $\mathbf{3 g}$ in $33 \%, 41 \%$, and $54 \%$ yields, respectively $(E / Z=94: 6-100: 0)$. In sharp contrast, the presence of a hydroxy group inhibited the desired phosphinylphosphination (see, alkyne 2f), probably because of the decomposition of $\mathrm{Ph}_{2} \mathrm{P}(\mathrm{O}) \mathrm{PPh}_{2}$. Furthermore, an electron-deficient alkyne such as methyl propiolate $(\mathbf{2 h})$ failed to provide the desired adduct (3h) [61]. 3-Phenyl-1-propyne (2i) and cyclohexylacetylene $(\mathbf{2 j})$ gave $3 \mathbf{i}$ and $\mathbf{3 j}$ in $41 \%$ and $65 \%$ yields, respectively. Again, an excellent stereoselectivity was observed. Moreover, terminal arylalkynes 2k-o were also toler- ated under the conditions to afford the desired adducts $\mathbf{3 k - 0}$ in moderate to good yields with high stereoselectivity.

We also investigated the phosphinylphosphination of some internal alkynes, $\mathbf{2 p}$ and $\mathbf{2 q}$, with $\mathrm{Ph}_{2} \mathrm{P}(\mathrm{O}) \mathrm{PPh}_{2}$, but did not afford any adduct (the starting alkynes were recovered unchanged) (Scheme 4). This is most probably because the internal alkynes are sterically bulkier than terminal alkynes, and therefore, the addition did not proceed (Scheme 4, reaction 1). On the other hand, reaction 2 in Scheme 4 indicates an example of the phosphinylphosphination of a terminal alkyne. The detailed analysis of the products in this reaction revealed the formation of $8 \%$ of the addition product $\mathbf{3 n}$ ', which might be formed by the addition of $\mathrm{Ph}_{2} \mathrm{P} \bullet$ to the alkyne. Noteworthy is that the capture of carbon radicals occurred only at the trivalent phosphorus site of $\mathrm{Ph}_{2} \mathrm{P}(\mathrm{O}) \mathrm{PPh}_{2}$. Therefore, the initiation step might also proceed via the attack of the carbon radical generated from V-40 at the trivalent phosphorus site to form $\mathrm{Ph}_{2} \mathrm{P}(\mathrm{O}) \bullet$ selectively.

With this information in mind, a plausible reaction pathway is shown in Scheme 5. Decomposition of the radical initiator (V-40) generates In $\bullet$ which attacks selectively at the trivalent phosphorus atom of $\mathrm{Ph}_{2} \mathrm{P}(\mathrm{O}) \mathrm{PPh}_{2}$ to form $\mathrm{Ph}_{2} \mathrm{P}(\mathrm{O}) \bullet$. Then, $\mathrm{Ph}_{2} \mathrm{P}(\mathrm{O}) \bullet$ adds to the terminal carbon of an alkyne to afford the carbon-centered radical A1. Radical A1 is captured by $\mathrm{Ph}_{2} \mathrm{P}(\mathrm{O}) \mathrm{PPh}_{2}$ to provide $\mathbf{A 2}$, regio- and stereoselectively [62].

\section{Conclusion}

In conclusion, a highly regio- and stereoselective phosphinylphosphination of alkynes with $\mathrm{Ph}_{2} \mathrm{P}(\mathrm{O}) \mathrm{PPh}_{2}$ has been successfully developed. The radical initiator V-40 can be used 


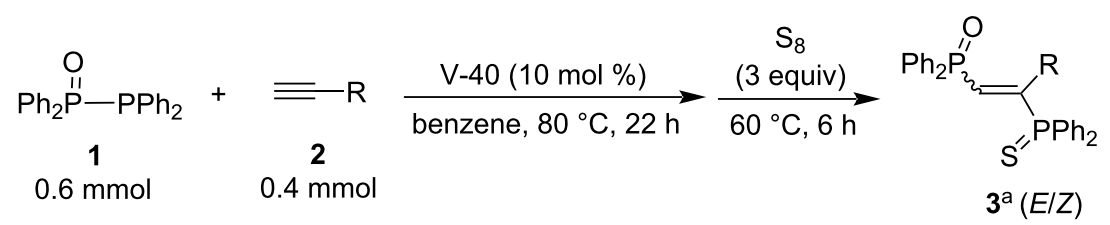<smiles>O=[Pb]=C(CC[Te])C(P)=S</smiles><smiles>CC(=O)OC(=C[PH](=O)Pc1ccccc1)C(P)=S</smiles><smiles>CC(C)CC/C(=C\P(O)c1ccccc1)[P+](=S)[In]</smiles><smiles>CCC[PH+](=O)/C=C(/[Pb])CCCCl</smiles><smiles>N#CCCC/C(=C\[PH](=O)P)[Pb](P)=S</smiles>

3a, $67 \%(99: 1)$

3b, 71\% (99:1)

3c, $83 \%(95: 5)$

3d, 33\% (94:6)

3e, $41 \%(99: 1)$<smiles>O=[PH+]([PH])C=C(CCCO)C(=S)Pc1ccccc1</smiles>

3f, N.D. ${ }^{b}$<smiles>COC(=O)CCC/C(=C\[PH](=O)c1ccccc1)[P+](=S)[S-]</smiles>

$3 g, 54 \%(100: 0)$<smiles>COC(=O)C(=CP=O)[PH](=S)c1ccccc1</smiles>

3h, N.D. ${ }^{b}$<smiles>O=[PH+]([PH])/C=C(/Cc1ccccc1)[Pb](P)=S</smiles>

3i, $41 \%(97: 3)$<smiles>O=P/C=C(/C(=S)Pc1ccccc1)C1CCCCC1</smiles>

3j, $65 \%(94: 6)$<smiles>O=[PH](C=C(c1ccc(F)cc1)[PH](=S)Pc1ccccc1)c1ccccc1</smiles>

3k, $80 \%(98: 2)$<smiles>COc1ccc(C(=C[PH](=O)c2ccccc2)C(=S)Pc2ccccc2)cc1</smiles>

3I, $85 \%(99: 1)$<smiles>CC(C)(C)c1ccc(/C(=C\[PH](=O)c2ccccc2)[P+](=S)[S-])cc1</smiles>

$3 \mathrm{~m}, 78 \%(99: 1)$<smiles>COc1ccc(C(=C[PH](=O)Pc2ccccc2)C(=S)Pc2ccccc2)cc1</smiles>

3n, $81 \%(98: 2)$

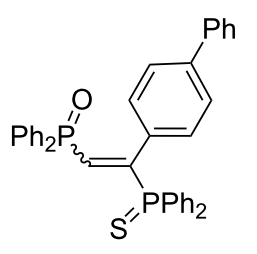

3o, $45 \%(93: 7)$

Scheme 3: Phosphinylphosphination of various terminal alkynes 2 with 1. ${ }^{a}$ Isolated yields. V-40 $=1,1$ '-azobis(cyclohexane-1-carbonitrile). ${ }^{b}$ Repeated 2 times.

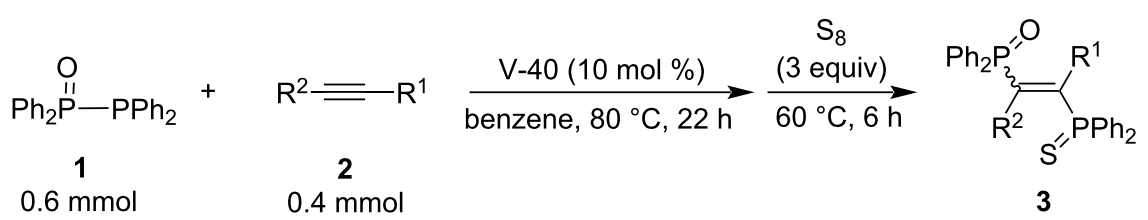

$\mathrm{R}^{1}=-\mathrm{Ph} ; \mathrm{R}^{2}=-\mathrm{Et} ; 3 \mathbf{p}(0 \%)$

$\mathrm{R}^{1}=-\mathrm{C}_{3} \mathrm{H}_{9} \mathrm{Ph} ; \mathrm{R}^{2}=-\mathrm{Me} ; \mathbf{3 q}(0 \%)$

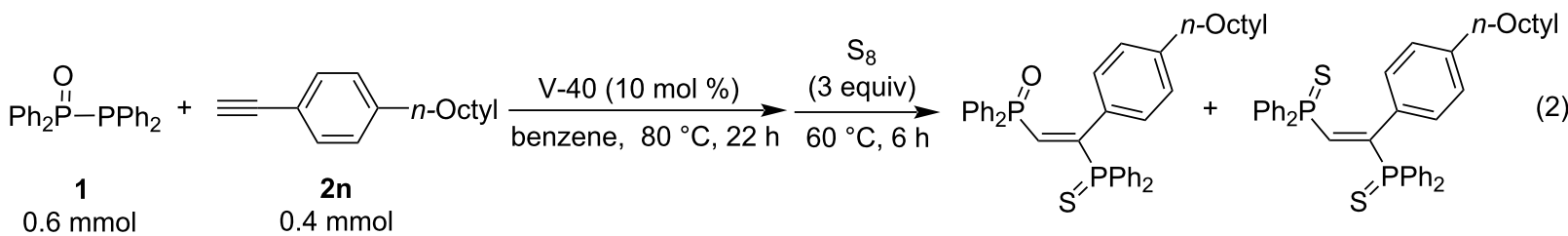

3n, $81 \%$

Scheme 4: Attempted radical addition to internal alkynes and insight into the addition to $\mathbf{2 n}$. 


$$
\mathrm{Ph}_{2} \stackrel{\mathrm{II}}{\mathrm{P}}-\mathrm{PPh}_{2} \stackrel{\text { radical initiator }(\mathrm{In})}{\longrightarrow} \stackrel{\stackrel{\mathrm{O}}{\longrightarrow}}{\mathrm{Ph}_{2} \mathrm{P} \cdot}+\mathrm{In}-\mathrm{PPh}_{2}
$$

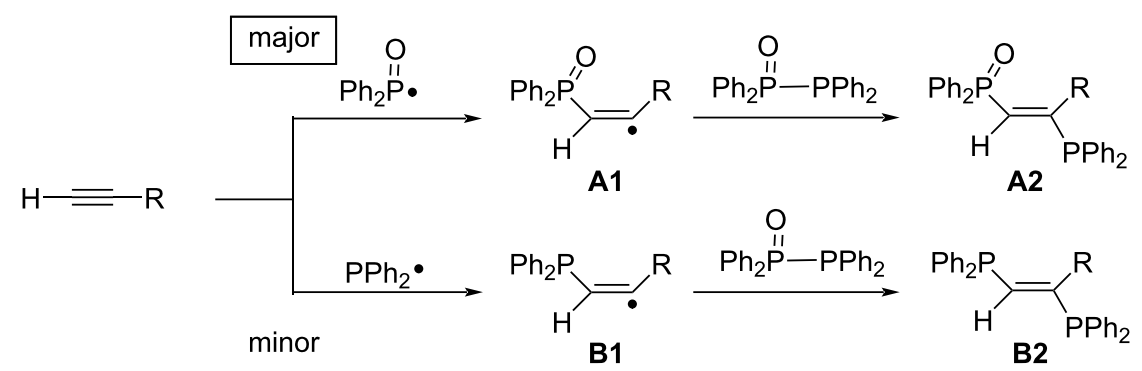

Scheme 5: A plausible reaction pathway for the radical addition of $\mathrm{Ph}_{2} \mathrm{P}(\mathrm{O}) \mathrm{PPh}_{2}$ to terminal alkynes.

to selectively generate $\mathrm{Ph}_{2} \mathrm{P}(\mathrm{O}) \bullet$ as an important species to regioselectively afford 1-phosphinyl-2-phosphinoalkenes. This method can be applied to a wide range of terminal alkynes. We believe that the excellent stereoselectivity to give $(E)$-isomers is effective for the stereoselective synthesis of $(E)$-bis(diphenylphosphino)ethylenes.

\section{Experimental}

\section{General comments}

Unless otherwise state, materials were obtained from commercial suppliers and purified by distillation. ${ }^{1} \mathrm{H}$ NMR spectra were recorded on a JEOL JNM-ECS400 (400 MHz) spectrometer or JEOL JNM-ECX400 (400 MHz) FT spectrometer in $\mathrm{CDCl}_{3}$ as the solvent with tetramethylsilane (TMS) as an internal standard. ${ }^{13} \mathrm{C}$ NMR spectra were taken mainly on JEOL JNMECS400 (100 MHz) and JEOL JNM-ECX400 (100 MHz) FT spectrometers in $\mathrm{CDCl}_{3}{ }^{31} \mathrm{P} \mathrm{NMR}$ spectra were recorded on a JEOL JNM-ECX400 (162 MHz) FT spectrometer in $\mathrm{CDCl}_{3}$ with $85 \% \mathrm{H}_{3} \mathrm{PO}_{4}$ solution as an external standard or a Bruker BioSpin Ascend 400 spectrometer (162 MHz). ${ }^{19} \mathrm{~F}$ NMR spectra were recorded on a Bruker BioSpin Ascend 400 spectrometer (377 MHz). IR spectra were recorded on JASCO FT/IR680Plus instrument. High-resolution mass spectra (HRMS) were recorded on a Bruker micrOTOF II ESI(+)/TOF instrument.

\section{General procedure for the phosphinylphos- phination of alkynes}

$\mathrm{Ph}_{2} \mathrm{P}(\mathrm{O}) \mathrm{PPh}_{2}(1,0.6 \mathrm{mmol})$ and an alkyne (2, $\left.0.4 \mathrm{mmol}\right)$ were placed in a Schlenk tube with $\mathrm{CDCl}_{3}$ or benzene (super dehydrated) under argon atmosphere. $\mathrm{V}-40$ was added to the mixture, and then the reaction was heated at $80{ }^{\circ} \mathrm{C}$ and stirred for $22 \mathrm{~h}$. After the reaction was complete, sulfur ( 3 equiv) was added under inert atmosphere and then the mixture was stirred at $60{ }^{\circ} \mathrm{C}$ for $6 \mathrm{~h}$ to provide the stable adduct 3 . The purification of the products was performed by silica gel column chromatography using isohexane/MeOAc as an eluent.

\section{Supporting Information}

\section{Supporting Information File 1}

Characterization data and copies of NMR spectra. [https://www.beilstein-journals.org/bjoc/content/ supplementary/1860-5397-17-72-S1.pdf]

\section{Funding}

D.P.T. is grateful for the support of the Japanese Government (Monbukagakusho: MEXT) Scholarship. This research was supported by JSPS KAKENHI (B, 19H02791), (B, 19H02756), and (19K17746), from the Ministry of Education, Culture, Sports, Science and Technology, Japan, and by Kyoto-NAIST Advanced Nanotechnology Network.

\section{ORCID ${ }^{\circledR}$ iDs}

Shintaro Kodama - https://orcid.org/0000-0003-4190-9539

\section{References}

1. Quin, L. D. Guide to Organophosphorus Chemistry; John Wiley \& Sons: New York, NY, USA, 2000.

2. Dutartre, M.; Bayardon, J.; Jugé, S. Chem. Soc. Rev. 2016, 45, 5771-5794. doi:10.1039/c6cs00031b

3. Tang, W.; Zhang, X. Chem. Rev. 2003, 103, 3029-3070. doi:10.1021/cr020049i

4. Wang, Z.; Liu, J. Beilstein J. Org. Chem. 2020, 16, 3015-3031. doi:10.3762/bjoc. 16.251

5. Cabri, W.; Candiani, I. Acc. Chem. Res. 1995, 28, 2-7. doi:10.1021/ar00049a001

6. Li, X.; Shi, X.; Li, X.; Shi, D. Beilstein J. Org. Chem. 2019, 15, 2213-2270. doi:10.3762/bjoc. 15.218 
7. Surry, D. S.; Buchwald, S. L. Angew. Chem., Int. Ed. 2008, 47, 6338-6361. doi:10.1002/anie.200800497

8. Fleckenstein, C. A.; Plenio, H. Chem. Soc. Rev. 2010, 39, 694-711. doi:10.1039/b903646f

9. Nakano, T.; Miyazaki, K.; Kamimura, A. J. Org. Chem. 2014, 79, 8103-8109. doi:10.1021/j05013042

10. Di Giacomo, M.; Serra, M.; Brusasca, M.; Colombo, L. J. Org. Chem. 2011, 76, 5247-5257. doi:10.1021/jo2002962

11. Oyamada, J.; Sakai, M.; Yamada, Y.; Kitamura, T. Bull. Chem. Soc. Jpn. 2013, 86, 129-137. doi:10.1246/bcsj.20120233

12. Daniels, D. S. B.; Jones, A. S.; Thompson, A. L.; Paton, R. S.; Anderson, E. A. Angew. Chem., Int. Ed. 2014, 53, 1915-1920. doi:10.1002/anie.201309162

13. Midya, G. C.; Parasar, B.; Dhara, K.; Dash, J. Org. Biomol. Chem. 2014, 12, 1812-1822. doi:10.1039/c3ob42365d

14. Locascio, T. M.; Tunge, J. A. Chem. - Eur. J. 2016, 22, 18140-18146. doi:10.1002/chem.201603481

15. Azizi, K.; Madsen, R. ChemCatChem 2018, 10, 3703-3708. doi:10.1002/cctc.201800677

16. Fu, L.; Chen, Q.; Wang, Z.; Nishihara, Y. Org. Lett. 2020, 22, 2350-2353. doi:10.1021/acs.orglett.0c00542

17. Hashimoto, T.; Ishimaru, T.; Shiota, K.; Yamaguchi, Y. Chem. Commun. 2020, 56, 11701-11704. doi:10.1039/d0cc05246a

18. Chan, J. Z.; Yesilcimen, A.; Cao, M.; Zhang, Y.; Zhang, B.; Wasa, M. J. Am. Chem. Soc. 2020, 142, 16493-16505. doi:10.1021/jacs.0c08599

19. Dondi, S.; Nardelli, M.; Pelizzi, C.; Pelizzi, G.; Predieri, G. J. Chem. Soc., Dalton Trans. 1985, 487-491. doi:10.1039/dt9850000487

20. Niu, S.-J.; Liu, X.-F.; Yu, X.-Y.; Wu, H.-K. J. Coord. Chem. 2017, 70, 2202-2211. doi:10.1080/00958972.2017.1340645

21. Santhoshkumar, R.; Mannathan, S.; Cheng, C.-H. J. Am. Chem. Soc. 2015, 137, 16116-16120. doi:10.1021/jacs.5b10447

22. Asako, S.; llies, L.; Nakamura, E. J. Am. Chem. Soc. 2013, 135, 17755-17757. doi:10.1021/ja4106368

23. Sun, Z.-M.; Zhang, J.; Manan, R. S.; Zhao, P. J. Am. Chem. Soc. 2010, 132, 6935-6937. doi:10.1021/ja102575d

24. Brandys, M.-C.; Puddephatt, R. J. J. Am. Chem. Soc. 2002, 124, 3946-3950. doi:10.1021/ja0113293

25. Lozano, E.; Nieuwenhuyzen, M.; James, S. L. Chem. - Eur. J. 2001, 7, 2644-2651.

doi:10.1002/1521-3765(20010618)7:12<2644::aid-chem26440>3.0.co; 2-3

26. DelNegro, A. S.; Woessner, S. M.; Sullivan, B. P.; Dattelbaum, D. M.; Schoonover, J. R. Inorg. Chem. 2001, 40, 5056-5057. doi:10.1021/ic001401i

27. Ye, J.; Zhang, J.-Q.; Saga, Y.; Onozawa, S.-y.; Kobayashi, S.; Sato, K.; Fukaya, N.; Han, L.-B. Organometallics 2020, 39, 2682-2694. doi:10.1021/acs.organomet.0c00295

28. Werncke, C. G.; Müller, I. Chem. Commun. 2020, 56, 2268-2271. doi:10.1039/c9cc08968c

29. Narsireddy, M.; Yamamoto, Y. J. Org. Chem. 2008, 73, 9698-9709. doi:10.1021/jo801785r

30. Brunner, H.; Muschiol, M.; Zabel, M. Synthesis 2008, 405-408. doi:10.1055/s-2008-1032133

31. Boelter, S. D.; Davies, D. R.; Milbrandt, K. A.; Wilson, D. R.; Wiltzius, M.; Rosen, M. S.; Klosin, J. Organometallics 2020, 39 , 967-975. doi:10.1021/acs.organomet.9b00721

32. Yorimitsu, H. Beilstein J. Org. Chem. 2013, 9, 1269-1277. doi:10.3762/bjoc. 9.143
33. Kawaguchi, S.-i.; Ogawa, A. Future Trends in Organophosphorus Chemistry. In Organophosphorus Chemistry: From Molecules to Applications; laroshenko, V., Ed.; Wiley-VCH: Weinheim, Germany, 2019; pp 545-556. doi:10.1002/9783527672240.ch11

34. Hirano, K.; Miura, M. Tetrahedron Lett. 2017, 58, 4317-4322. doi:10.1016/j.tetlet.2017.10.018

35. Kondoh, A.; Yorimitsu, H.; Oshima, K. Chem. - Asian J. 2010, 5, 398-409. doi:10.1002/asia.200900447

36. Kawaguchi, S.-i.; Ogawa, A. Asian J. Org. Chem. 2019, 8, 1164-1173. doi:10.1002/ajoc.201900339

37. Taniguchi, T. Synthesis 2017, 49, 3511-3534. doi:10.1055/s-0036-1588481

38. Kawaguchi, S.-i.; Nagata, S.; Shirai, T.; Tsuchii, K.; Nomoto, A.; Ogawa, A. Tetrahedron Lett. 2006, 47, 3919-3922. doi:10.1016/j.tetlet.2006.03.165

39. Shirai, T.; Kawaguchi, S.-i.; Nomoto, A.; Ogawa, A. Tetrahedron Lett. 2008, 49, 4043-4046. doi:10.1016/j.tetlet.2008.04.068

40. Kawaguchi, S.-i.; Shirai, T.; Ohe, T.; Nomoto, A.; Sonoda, M.; Ogawa, A. J. Org. Chem. 2009, 74, 1751-1754. doi:10.1021/j08020067

41. Kawaguchi, S.-i.; Ohe, T.; Shirai, T.; Nomoto, A.; Sonoda, M.; Ogawa, A. Organometallics 2010, 29, 312-316. doi:10.1021/om9008982

42. Sato, Y.; Kawaguchi, S.-i.; Nomoto, A.; Ogawa, A. Angew. Chem., Int. Ed. 2016, 55, 9700-9703. doi:10.1002/anie.201603860

43. Sato, Y.; Kawaguchi, S.-i.; Nomoto, A.; Ogawa, A. Chem. - Eur. J. 2019, 25, 2295-2302. doi:10.1002/chem.201805114

44. Sato, Y.; Nishimura, M.; Kawaguchi, S.-i.; Nomoto, A.; Ogawa, A. Chem. - Eur. J. 2019, 25, 6797-6806. doi:10.1002/chem.201900073

45. Sato, A.; Yorimitsu, H.; Oshima, K. Angew. Chem., Int. Ed. 2005, 44, 1694-1696. doi:10.1002/anie.200462603

46. Yamamoto, Y.; Tanaka, R.; Ota, M.; Nishimura, M.; Tran, C. C.; Kawaguchi, S.-i.; Kodama, S.; Nomoto, A.; Ogawa, A. J. Org. Chem. 2020, 85, 14708-14719. doi:10.1021/acs.joc.0c02014

47. The stereochemistry of $3 a$ was determined by comparison with the previous data ( ${ }^{31} \mathrm{P}$ NMR data) of a structurally similar compound [45] The coupling constant $\left(J_{\mathrm{P}-\mathrm{P}}\right)$ value for $(E)$-isomer of $3 \mathrm{a}\left(J_{\mathrm{P}-\mathrm{P}}=56 \mathrm{~Hz}\right)$ is larger than that of $(Z)$-isomer $\left(J_{\mathrm{P}-\mathrm{P}}=17 \mathrm{~Hz}\right)$.

48. Zhao, Y.; Guo, D.; Liu, X.; Wang, L.; Jiang, N.; Wang, X. Appl. Opt. 2016, 55, 6596-6600. doi:10.1364/ao.55.006596

49. Breeze, J.; Tan, K.-J.; Richards, B.; Sathian, J.; Oxborrow, M.; Alford, N. M. Nat. Commun. 2015, 6, 6215. doi:10.1038/ncomms7215

50. Nguyen, V.-H.; Lin, S. D.; Wu, J. C.-S.; Bai, H. Beilstein J. Nanotechnol. 2014, 5, 566-576. doi:10.3762/bjnano.5.67

51. Anevsky, S.; Krutikov, V.; Minaeva, O.; Minaev, R.; Senin, D.; Hollandt, J.; Taubert, D. R. Appl. Opt. 2013, 52, 5152-5157. doi:10.1364/ao.52.005152

52. Otomura, N.; Okugawa, Y.; Hirano, K.; Miura, M. Org. Lett. 2017, 19, 4802-4805. doi:10.1021/acs.orglett.7b02223

53. Otomura, N.; Okugawa, Y.; Hirano, K.; Miura, M. Synthesis 2018, 50, 3402-3407. doi:10.1055/s-0037-1609447

54. Otomura, N.; Hirano, K.; Miura, M. Org. Lett. 2018, 20, 7965-7968. doi:10.1021/acs.orglett.8b03534

55. Kato, Y.; Otomura, N.; Hirano, K.; Miura, M. J. Org. Chem. 2020, 85, 5981-5994. doi:10.1021/acs.joc.0c00417

56. Huang, T.; Saga, Y.; Guo, H.; Yoshimura, A.; Ogawa, A.; Han, L.-B. J. Org. Chem. 2018, 83, 8743-8749. doi:10.1021/acs.joc.8b01042

57. Liu, L.; Zhou, D.; Dong, J.; Zhou, Y.; Yin, S.-F.; Han, L.-B. J. Org. Chem. 2018, 83, 4190-4196. doi:10.1021/acs.joc.8b00187 
58. Guo, H.; Yoshimura, A.; Chen, T.; Saga, Y.; Han, L.-B. Green Chem. 2017, 19, 1502-1506. doi:10.1039/c6gc03240k

59. Hirai, T.; Han, L.-B. Org. Lett. 2007, 9, 53-55. doi:10.1021/ol062505।

60. Furthermore, some additional experiments were conducted in several reaction time to consider whether isomerization from $(E)-3 a$ to $(Z)-3 a$ (or from (Z)-isomer to $(E)$-isomer) is occurred or not (Reaction conditions: similar to Table 1, entry 6). After $6 \mathrm{~h}, 8 \mathrm{~h}$ and $22 \mathrm{~h}$, a 99:1 ratio of $E / Z$ isomers was obtained $(22 \%, 35 \%$, and $73 \%$ yields of $3 \mathbf{a}$, respectively). These results clearly indicate that there is no $E \leftrightarrow Z$ isomerization under the present reaction conditions.

$61.90 \%$ of $\mathbf{2 h}$ (methyl propiolate) was recovered after reaction (determined by ${ }^{1} \mathrm{H}$ NMR spectroscopy). We consider that the addition of $\mathrm{Ph}_{2} \mathrm{P}(\mathrm{O}) \cdot($ electrophilic radical) to $\mathbf{2 h}$ (electron-deficient alkyne) hardly proceeds due to polarity mismatching.

62. In the radical addition reaction, when a radical attacks a terminal alkyne, a vinyl radical is usually generated. When the vinyl radical is captured by $\mathrm{Ph}_{2} \mathrm{P}(\mathrm{O}) \mathrm{PPh}_{2} 1$, the trans form has priority because of the bulkiness of $\mathbf{1}$ (the cis form is hardly captured by $\mathbf{1}$ ).

\section{License and Terms}

This is an Open Access article under the terms of the Creative Commons Attribution License (https://creativecommons.org/licenses/by/4.0). Please note that the reuse, redistribution and reproduction in particular requires that the author(s) and source are credited and that individual graphics may be subject to special legal provisions.

The license is subject to the Beilstein Journal of Organic Chemistry terms and conditions:

(https://www.beilstein-journals.org/bjoc/terms)

The definitive version of this article is the electronic one which can be found at: https://doi.org/10.3762/bjoc. 17.72 